\title{
Developing a Data-Literate Workforce through BLUE: Biodiversity Literacy in Undergraduate Education
}

\author{
Elizabeth R. Ellwood ${ }^{\ddagger}$, Anna Monfils ${ }^{\S}$, Lisa Whitel, Debra Linton ${ }^{\S}$, Natalie Douglas ${ }^{\S}$, Molly Phillips ${ }^{\Uparrow}$ \\ ₹ Natural History Museum of Los Angeles County, Los Angeles, United States of America \\ $\S$ Central Michigan University, Mt. Pleasant, United States of America \\ | UC Museum of Paleontology, Berkeley, United States of America \\ I University of Florida, Gainesville, United States of America
}

Corresponding author: Elizabeth R. Ellwood (ellwoodlibby@gmail.com)

Received: 14 Jun 2019 | Published: 25 Jun 2019

Citation: Ellwood E, Monfils A, White L, Linton D, Douglas N, Phillips M (2019) Developing a Data-Literate Workforce through BLUE: Biodiversity Literacy in Undergraduate Education. Biodiversity Information Science and Standards 3 : e37339. https://doi.org/10.3897/biss.3.37339

\section{Abstract}

The biodiversity sciences have experienced a rapid mobilization of data that has increased our capacity to investigate large-scale issues of critical importance (e.g., climate change and its impacts, zoonotic disease transmission, sustainable resource management, impacts of invasive species, and biodiversity loss). Several initiatives are underway to aggregate and mobilize these biodiversity, environmental, and ecological data resources (iDigBio, NEON, GBIF, iNaturalist, etc.). This requires a new set of skills for the 21st century biodiversity scientist; who is required to be fluent in integrative fields spanning evolutionary biology, systematics, ecology, geology, and environmental science and possess the quantitative, computational, and data skills to conduct research using large and complex datasets. The biodiversity science community has recognized a need to unite biodiversity and data sciences and improve data literacy in the emerging science workforce. The NSF-funded Biodiversity Literacy in Undergraduate Education (BLUE; biodi versityliteracy.com) is working to bridge a gap between efforts that currently exists to promote data literacy pre-college and professional development for those pursuing careers in biodiversity science. The BLUE network is developing strategies and materials to infuse biodiversity data into the core of the undergraduate science curriculum, facilitating broad- 
scale adoption of biodiversity data literacy competencies, and improving undergraduate biology training to meet increasing workforce demands in data and biodiversity sciences. The BLUE network has four major goals: 1) Cultivate a diverse and inclusive network of biodiversity researchers, data scientists, and biology educators focused on undergraduate data-centric biodiversity education; 2) build community consensus on core biodiversity data literacy competencies; 3) develop strategies and exemplar materials to guide the integration of biodiversity data literacy competencies into introductory undergraduate biology curricula; and 4) extend the network to engage a broader community of undergraduate educators in biodiversity data literacy efforts.

The BLUE community continues to grow and build new partnerships and initiatives across the biodiversity science community. In year two of the BLUE network we have been focusing efforts building the community, developing and disseminating exemplar educational materials, and defining core biodiversity data literacy skills and competencies. We will present our current and ongoing work and ways in which members of the biodiversity_next community can be involved in shaping the biodiversity science of the future, while addressing the needs of a changing planet.

\section{Keywords}

biodiversity, data, literacy, BLUE, undergraduate, education

\section{Presenting author}

Elizabeth R. Ellwood

\section{Presented at}

Biodiversity_Next 2019 